DOI: 10.20472/IAC.2018.036.053

\title{
YUN ZHENG
}

Xinyang Normal University, China

JIE HUANG

Xinyang Normal University, China

JIANFENG WANG

Millersville University of Pennsylvania , United States

\section{FACTORS INFLUENCING THE SPATIAL CORRELATION NETWORK OF ENERGY ENVIRONMENTAL EFFICIENCY}

\begin{abstract}
:
Improving energy and environmental efficiency is an inevitable choice for developing countries to achieve sustainable economic and social development. Using VAR Granger causality test method (Granger, 1969), this study identifies the spatial correlation of energy environmental efficiency based on provincial panel data sample between 1995 and 2015 in China; further through the QAP analysis model (Liu, 2014), the factors influencing the spatial correlation network of energy environmental efficiency is empirically analyzed. The results show that the differences of economic development level, energy consumption structure, industrial structure, environmental regulation and technological innovation are significantly correlated with spatial correlation network of energy environmental efficiency; similar economic development level, technical level and industrial structure are beneficial to the formation of spatial correlation network of energy environmental efficiency while the differences of energy consumption structure and environmental regulation have little impact on this process.
\end{abstract}

\section{Keywords:}

energy environmental efficiency; spatial correlation network; impact factors.

JEL Classification: Q43, Q48, Q40 


\section{Introduction}

The increase of total energy consumption and aggravation of environmental pollution has become an important obstacle to the sustainable development of economic society in developing countries. The establishment of circulating and efficient resource utilization system, comprehensively improving the energy-environmental efficiency (EEE), promoting the transformation of economic development mode and realizing green development, are not only the strategic choice of developing countries in the long run, but also the inevitable requirement to solve the resource and environment problems. However, under the joint action of different economic structure, technology level and energy consumption mode, EEE presents a complex spatial correlation network (SCN) structure. Therefore, it has become the future research trend of the academia to re-examine the space-time relationship and enhance strategy of EEE from the network perspective. With this background, correctly identifying the spatial correlation of EEE, in-depth analysis of the factors influencing the SCN of EEE has important theoretical significance and practical implications for developing countries to improve EEE and realize green development.

Since Krugman (1995) establishes a complete space model, the spatial impact of economic activities has gradually aroused the attention of scholars. Meanwhile, with the theoretical breakthrough of spatial economics and the parallel development of econometric techniques, more and more scholars begin to study the spatial effect of energy efficiency. Kan and Luo (2010) analyze the relationship between urbanization and energy consumption intensity. Their results show that both urbanization and energy intensity have strong spatial dependence. Further energy efficiency is influenced not only by local urbanization and energy efficiency, but also by the urbanization and energy efficiency of neighboring provinces. Through the analysis of the spatial characteristics and influencing factors of energy efficiency in China using integrated Data Envelopment Analysis (DEA) and spatial econometric models, Shen's (2010) research finds that the EEE of the region is affected by both the local economy and the energy efficiency of neighboring regions. Xu and Guan's (2011) study reveals that not only there is a significant spatial correlation between energy efficiencies across regions, but also there is an increasing trend. Pan et al.'s (2014) research shows that energy efficiency among provinces in China has a significant spatial spillover effect.

There are many factors that affect EEE. They are mainly related to three aspects including structural factors, the main factors of behavior and external shocks. The structural factors encompass industrial structure and energy consumption structure. The main factors of behavior include the influence of government on environment (environmental regulation) and the environmental self-control ability of enterprise production, etc. External shocks factors include technological progress and economic development level, etc. (Wu, Dong 2016). Richard and Adam's (1999) study finds that if 
the industrial structure of a country or region has shifted from heavy industry to light industry, its energy consumption intensity will be greatly reduced. Using Divisia decomposition method, Fisher-Vanden et al. (2006) empirically analyze the structural effects of energy efficiency improvement, and find that industrial restructuring can significantly reduce energy consumption intensity based on the relevant data of large and medium-sized industrial enterprises between 1997 and 1999 in China. Yu's (2017) study reveals that advanced industrial structure has a significant positive impact on energy efficiency improvement. Sinton and Fridley (2000) find that significant reduction of the intensity of energy consumption is closely related to the residents' largescale use of natural gas, electricity and other energy sources based on his study of the energy intensity in China. Using the cross-country data, Chien and $\mathrm{Hu}$ (2007) find that if the share of a country's traditional energy sources (such as coal) rises, it will lead to a decline in the country's energy efficiency. Hirst (1991) indicates that government should and will be able to address the deficiencies and inefficiencies in energy allocation in the marketplace and increase energy efficiency through mandatory policies. Both Meng et al. (2013) and Wu et al. (2014) examine the level of industrial energy efficiency in different regions based on the level of regional economic development. Their studies show that the higher the level of economic development, the higher the efficiency of industrial energy.

The existing literature has laid a good foundation for the research of this paper, but there are some gaps: firstly, even though most studies have considered that the spatial spillover relationship of EEE mainly comes from the spillover effect of the adjacent regions, and the spillover effect is influenced by the distance between regions, few research examines the quantitative measure and description from the perspective of larger scope and wider spatial relationship; secondly, the previous research is based on the "attribute data" rather than "relational data". Attribute data can only reflect the current status of EEE, but cannot provide a comprehensive description of the spatial correlation "relationship" of the EEE; further, the current studies only verify that there is a spatial correlation effect of EEE from a spatial perspective, but few reveal the causes of spatial correlation of EEE.

Using Granger causality test method (Granger, 1969) within Vector Autoregression Model (VAR) model framework (Sims, 1980), this article identifies the spatial correlation of EEE from the "relationship" point of view. We analyze the factors influencing the formation of SCN of EEE using the technique of Quadratic Assignment Procedure (QAP) (Liu, 2014) in social network analysis. 


\section{Model Building and the Data Sources}

\subsection{Building the spatial network for EEE}

Based on previous research ( $\mathrm{Hu}$, et al., 2006), this paper defines EEE as energy efficiency considering environmental constraints within the overall factor framework. Supposing there are $j$ units to be evaluated $D U M_{j}(j=1,2, \cdots, J)$, each unit uses $i$ types of non-energy input $x_{i j}(i=1,2, \cdots, I)$ and $r$ types of energy input $e_{i j}(r=1,2, \cdots, R)$ in its production, producing $k$ types of expected output $y_{i j}(k=1,2, \cdots, K)$ and $h$ types of unexpected output $p_{h j}(h=1,2, \cdots, H)$. Using the environmental production technology analysis framework constructed by Färe and Love (1978), we construct a non-radial, input-output dual-direction window DEA model to measure the efficiency of EEE as formula (1):

$$
E_{m n}=\min \frac{1}{2}\left(\frac{1}{R} \sum_{r=1}^{R} \theta_{r}^{m n}+\frac{1}{H} \sum_{h=1}^{H} \varphi_{r}^{m n}\right), m=1,2, \cdots,(T-d+1) ; n=1,2, \cdots, d
$$

$E$ is labeled for EEE, $\theta_{r}$ for the energy input effect, $\varphi_{h}$ for the pollution emission effect. $m$ and $n$ indicate that the variable is the one at the $n^{\text {th }}$ time point in the $m^{\text {th }}$ window.

To investigate the spatial correlation effect of EEE, this study selects VAR Granger causality test method (Granger, 1969) to determine the relationship between interregional EEE. Firstly, we define the EEE time series for two regions as $\left\{x_{t}\right\}$ and $\left\{y_{t}\right\}$ respectively; secondly, we construct two VAR model to verify whether there is a Granger causality in EEE changes between the two regions:

$$
\left\{\begin{array}{l}
x_{t}=\alpha_{1}+\sum_{i=1}^{m} \beta_{1, i} x_{t-i}+\sum_{i=1}^{n} \gamma_{1, i} y_{t-i}+\varepsilon_{1, t} \\
y_{t}=\alpha_{2}+\sum_{i=1}^{p} \beta_{2, i} x_{t-i}+\sum_{i=1}^{q} \gamma_{2, i} y_{t-i}+\varepsilon_{2, t}
\end{array}\right.
$$

$\alpha_{j 1}, \beta_{j}, \gamma_{j}(j=1,2)$ are the parameters to be evaluated. $\left\{\varepsilon_{j, t}\right\}(j=1,2)$ refers the residual item, and it follows the standard normal distribution. $m, n, p, q$ refer the lagrange order of autoregression. If the test results indicate that area $\mathrm{A}$ is the Granger cause of area B, it means area A has significant spatial correlation effect on area B. Accordingly, a line directed from $A$ to $B$ is drawn between the two regions in order to construct the SCN matrix of EEE. 


\subsection{Econometric model settings}

Based on the literature(Cheng et al,2013;Lin and Liu,2015;Wang and Xiang,2014;Pan, 2012), this paper proposes the factors affecting the spatial correlation of EEE as follows: (1) regional differences in economic development. Under the function of the market mechanism, the factors of production are more likely to flow in regions with similar economic development level, so EEE is more likely to be correlated between regions with similar economic development level; (2) regional differences in energy consumption structures. The difference in energy consumption structure is mainly manifested in the use of fossil fuels. EEE is quite different under different energy consumption structure. Therefore, the relatively different energy consumption structure may be more conducive to the formation of EEE spatial relationship; (3) the regional differences in the industrial structure. EEE is closely related to the development of tertiary industry. The rapid development of the tertiary industry is helpful in strengthening the spatial relationship of EEE; (4) regional differences in environmental regulations. The greater the difference of environmental regulation, the higher the probability that enterprises located in regions with higher environmental regulations will shift to regions with lower intensity of environmental regulations, which leads to the flow of production factors and enhances the correlation effect of EEE; (5) the regional differences in technical innovation levels. The difference of technological innovation level may hinder the transfer and absorption of new technology among regions, which is unfavorable to the formation of the relationship between EEE. Based on the above impact factors, the model is proposed as below:

$$
D=f\left(P G_{C}, E S_{C}, I S_{C}, E R_{C}, T I_{C}\right)
$$

The dependent variable $D$ is based on the binary network matrix of spatial correlation determined by the VAR Granger causality test model in formula 2. $P G_{C}, E S_{C}, I S_{C}, E R_{C}, T I_{C}$ refer respectively the difference matrix of economic development level, the difference matrix of energy consumption structure, the difference matrix of industrial organization, the difference matrix of environmental regulation intensity and the difference matrix of technological innovation level. Because this study uses "relational" data, there is a high similarity between independent variables. In order to avoid the measurement error caused by multiple collinearity, this research adopts QAP method to empirically examine the influencing factors of the spatial correlation network of EEE.

\subsection{Data sources and processing}

This study takes China's inter-provincial panel data from 1995 to 2015 as a sample. To measure the EEE, we use "Perpetual Inventory Method" adopted by Shan (2008) for capital investment. Formula $K_{t}=I_{t}+(1-\delta) K_{t-1}$ is applied. $K_{t}$ and $K_{t-1}$ represent the $t^{\text {th }}$ and $(t-1)^{\text {th }}$ period fixed capital stock; $I_{t}$ represents the fixed asset investment amount in 
regional I at the $t$ period; $\delta_{i t}$ represents the depreciation rate $(10.96 \%)$, which is capital stock in every province calculated by 1978 base period; the number of labor force is expressed by the total number of employed people at the end of the year in each region; the energy input is expressed by the total energy consumption in each province; expected output is the actual GDP calculated by 1978 constant price for each province; non-expected output includes sulphur dioxide and carbon dioxide emissions. Among them, sulfur dioxide emissions data come from the published data of every year's "China Statistical Yearbook" and "China Environment Statistics Yearbook" with the unit of 10,000 tons; carbon dioxide emissions data are calculated based on the method provided by 2006 IPCC (Intergovernmental Panel on Climate Change) Guidelines for National Greenhouse Gas Emission Inventories" (www.ipcc-nggip.iges.or.jp).

In terms of impact factors, the real GDP per capita difference calculated on the basis of year 1978 in each province is used to represent the economic development level of the differential matrix; the difference matrix of energy consumption structure is measured by the difference of coal consumption as the proportion of total energy consumption in each province; the difference matrix of industrial structure is represented by the differences in tertiary industry as share of GDP in each province; the difference matrix of the intensity of environmental regulation is characterized by the difference of the pollution control investment in the proportion of industrial value added; and the difference matrix of technological innovation level is represented by the difference in the number of approved patents owned by every hundred scientific and technical personnel.

For formula 3 , all indicators are made up of the absolute difference between the means in each province from 1995 to 2015 except indicator $D$.

\section{EEE Spatial Correlation Network Impact Factor Analysis}

\subsection{QAP correlation analysis}

This article first applies the QAP correlation analysis to examine the correlation between the SCN of EEE and the factors proposed in section 2.2. The value of the correlation coefficient reflects the extent of a variable impact on SCN structure of EEE. The maximum and minimum values are the ones that occur during the repeat sampling of 10,000 times respectively. $P \geq 0 、 P \leq 0$ represnt the probabilities that the correlation coefficient obtained in the sampling process are greater (smaller) than or equal to the final correlation coefficient. The correlation analysis results are displayed in Table 1 which shows that the correlation coefficients between economic development level difference, energy consumption structure difference, industrial structure difference, difference of environmental regulation and technological innovation level and the EEE of SCN are are all significant at $1 \%$ level. It is indicated that these five factors have important influence on the formation of SCN of EEE. Among them, the correlation coefficients of the economic 
development level difference, the industrial structure difference and the technological innovation level difference are negative, which shows that the similar development stage and the industrial structure as well as the similar technical level are the important factors of spatial correlation and spatial spillover of EEE. The correlation coefficients of both energy consumption structure and environmental regulation are positive, which shows that the regional differences of energy consumption structure and environmental regulation are beneficial to the formation of SCN of EEE.

\section{Table 1: QAP correlation analysis of influencing factors}

\begin{tabular}{lllllllll}
\hline $\begin{array}{l}\text { Variable } \\
\text { name }\end{array}$ & $\begin{array}{l}\text { Actual } \\
\text { correlation } \\
\text { coefficient }\end{array}$ & $\begin{array}{l}\text { Significa } \\
\text { nt level }\end{array}$ & $\begin{array}{l}\text { Coefficient } \\
\text { mean }\end{array}$ & $\begin{array}{l}\text { Standard } \\
\text { deviation }\end{array}$ & $\begin{array}{l}\text { Minimum } \\
\text { value }\end{array}$ & $\begin{array}{l}\text { Maximum } \\
\text { Value }\end{array}$ & $P \geq 0$ & $P \leq 0$ \\
\hline$P G_{C}$ & -0.035 & 0.000 & -0.001 & 0.011 & -0.210 & 0.225 & 1.000 & 0.000 \\
$E S_{C}$ & 0.358 & 0.002 & 0.000 & 0.034 & -0.251 & 0.356 & 0.002 & 0.998 \\
$I S_{c}$ & -0.106 & 0.005 & -0.003 & 0.113 & -0.225 & 0.228 & 0.995 & 0.005 \\
$E R_{C}$ & 0.119 & 0.000 & 0.001 & 0.051 & -0.265 & 0.259 & 0.000 & 1.000 \\
$T I_{c}$ & -0.082 & 0.003 & -0.000 & 0.032 & -0.214 & 0.273 & 0.998 & 0.002 \\
\hline
\end{tabular}

\subsection{QAP regression analysis}

QAP regression results are shown on Table 2. The calculated adjusted coefficient of determination is 0.268 after 10,000 times random replacement. This indicates the discrepancy matrix formed by the differences of regional economic development level, energy consumption structure, industrial structure, environmental regulation and technological innovation level can explain about $27 \%$ of the changes in the SCN structure of EEE. The probability A and probability B represent the probability that the regression coefficients produced in the random permutation process are greater than or equal to the final regression coefficient respectively. The regression coefficient of regional economic development difference matrix is significant at the level of $1 \%$, which shows that the smaller the difference of economic development between regions, the more favorable to the formation of SCN of EEE. On the one hand, the similar level of economic development means that these areas are basically in the same stage of development, and have similar demand for economic growth and environmental improvement, which leads to the convergence of EEE, and strengthens the spatial network of EEE; on the other hand, with the market mechanism, the production factors are easier to flow between regions with similar economic development level, thus objectively creating conditions for the EEE in the generation of the correlation effect. The regression coefficient of the industrial structure difference matrix is significantly negative on the level of $10 \%$, indicating that similar industrial structures between regions have a significant impact on the formation of EEE spatial network. On the one hand, the similarity of industrial structure means the similar development stage; on the other hand, similar industrial 
structure will to some extent enhance the economic and technical links between regions, thus facilitating the formation of the SCN of EEE. The regression coefficient of the technology innovation difference matrix is negative at a significant level of $5 \%$, indicating that the similarity of the technical level between regions is conducive to the formation of SCN of EEE. The similar technical level is the basis for communication and exchange between regions. The smaller the technology gap, the more conducive it is to the interregional capital and technology spillover and absorption, so that the spatial network structure of EEE becomes more stable. In the QAP regression analysis of energy consumption structure and environmental regulation difference matrices, the coefficients are not significant even though they are positive, which indicates that the differences of energy consumption structure and environmental regulation do not significantly affect the formation of SCN of EEE.

Table 2: QAP regression analysis of influencing factors

\begin{tabular}{llllll}
\hline Variable & $\begin{array}{l}\text { Non-normalized } \\
\text { regression } \\
\text { coefficients }\end{array}$ & $\begin{array}{l}\text { Normalized } \\
\text { regression } \\
\text { coefficients }\end{array}$ & $\begin{array}{l}\text { Visibility } \\
\text { probability }\end{array}$ & probability A & probability B \\
\hline $\begin{array}{l}\text { Intercept } \\
\text { item }\end{array}$ & 0.561 & 0.000 & - & - & - \\
$P G_{c}$ & -0.026 & -0.751 & 0.002 & 0.998 & 0.002 \\
$E S_{c}$ & 0.031 & 0.657 & 0.128 & 0.128 & 0.872 \\
$I S_{c}$ & -0.005 & -0.063 & 0.054 & 0.946 & 0.054 \\
$E R_{C}$ & 0.003 & 0.216 & 0.223 & 0.223 & 0.777 \\
$T I_{c}$ & -0.012 & -0.085 & 0.014 & 0.986 & 0.014 \\
\hline
\end{tabular}

\section{Conclusions}

Using VAR Granger causality test model, this study identifies the spatial correlation of EEE and empirically analyzes the factors that influence the SCN through the social network analysis method. The findings show that the differences of energy consumption structure and environmental regulation intensity have significant positive correlations with the SCN structure of EEE; The differences of regional economic development, industrial structure and the level of technological innovation have significant negative correlations with the SCN structure of EEE; similar economic development level, technical level and industrial structure are beneficial to the formation of SCN structure of EEE while the differences of energy consumption structure and environmental regulation have little influence on this process.

Compared to previous studies, this research uses social network analysis method and empirically analyzes the factors that influence the SCN of EEE based on relational data found in China. The practical implications are: (1) optimizing SCN structure of EEE and 
promoting SCN formation are the key to achieve cross-regional synergy improvement of EEE. On the one hand, we should actively explore effective ways to promote the spatial correlation of EEE, increase the spatial relationship, and create more channels for cross regional synergy of EEE; On the other hand, when developing and implementing strategies for improving EEE, we should not only focus on the size of "relational data", but also pay attention to the level of "relational data" , and gradually form "quantity-structure" driven cross-regional collaborative enhancement mechanism; (2) we should comprehensively consider the impact factors of the SCN of EEE, and exert the role of government macro-control and market mechanism to promote the spatial correlation of EEE. At one side, the government should adopt a "visible hand" to set differentiated intensity of environmental regulations in different regions, actively takes measures to reduce the gap of economy, technology and industry development between the lower EEE region and the higher region, strengthen the interconnection of EEE and promote EEE at the overall level of improvement; at another side, government should also give full play to the market "invisible hand", reduce government administrative intervention, utilize market mechanisms such as competition, supply and demand to enhance EEE to strengthen the mutual exchange between higher efficient regions and lower efficient regions, and promote the improvement of EEE in inefficient regions and reduce the spatial disequilibrium.

\section{References:}

CHENG, Y. Q, WANG, Z .Y. and ZHANG, S. Z. (2013). Spatial Econometric Analysis of Carbon Emission Intensity and its Driving Factors From Energy Consumption in China. Acta Geographica Sinica. 2013, Vol.68, No.10, s. 1418-1431.

CHIEN, T. and HU, J. L. (2007). Renewable Energy and Macroeconomic Efficiency of OECD and nonOECD Economies. Energy Policy. 2007, Vol.35, No.7, s. 3606-3615.

FÄRE, R. and LOVELL, C. A. K. (1978). Measuring the Technical Efficiency of Production. Journal of Economic Theory. 1978, Vol.9, No.1, s. 150-162.

FISHER-VANDEN, K., JEFFERSON, G. H., JINGKUI, M. and JIANYI, X. (2006). Technology Development and Energy Production in China. Energy economics. 2006, Vol. 28 No. 4, s. 690-705.

GRANGER, C. W. J. (1969). Investigating Causal Relations by Econometric Models and Cross-Spectral Methods. Econometrica. 1969, Vol.37, No.3, s. 424-438.

HU, J. L., WANG, S. C. and YEH, F. Y. (2006). Total-factor water efficiency of regions in China. Energy Policy. 2006, Vol.36, No.2, s. 821-833.

HIRST, E. (1991). Improving Energy Efficiency in the USA: The Federal Role. Energy Policy. 1991, Vol.19, No.6, s. 567-577.

http://www.ipcc-nggip.iges.or.jp/public/2006gl/pdf/0_Overview/V0_1_Overview.pdf (Extracted 11-30-2017) 
KAN, D. X. and LUO, L.W. (2010). Impact of Urbanization on Energy Intensity in China - Analysis Based on Spatial Econometrics. Contemporary Finance. 2010, No. 3, s.83- 88.

KRUGMAN, P. and VENABLES, A. J. (1995). The Seamless World: A Spatial Model of International Specialization. Social Science Electronic Publishing.

LIN, B. Q. and LIU, H. M. (2015).Do Energy and Environment Efficiency Benefit from Foreign Trade?-The Case of China's Industrial Sectors. Economic Research Journal. 2015, No. 9, s. 127-141.

LIU, J. (2014). Overall Network Analysis Handouts: UCNET Software Practical Guide. Shanghai: Gezhi Press, Shanghai People's Press.

MENG, X., KONG, Q. X. and WANG, L. J. (2013). New Industrialization Perspective on Industrial Energy Efficiency Differences in "Double Triangle" Metropolitan Areas-Based on HyperEfficiency DEA Empirical Study of Methods. Resource Science. 2013, Vol.35, No.6, s. 1202-1210.

PAN, W. Q. (2012). Regional Linkage and the Spatial Spillover Effects on Regional Economic Growth in China. Economic Research Journal.2012, No. 1, s. 54-65.

PAN, X. F., YANG, Y. and ZHANG, W. W. (2014). Spatial Spillover Effect of Regional Energy Efficiency in China. Journal of Management Engineering. 2014, Vol. 28, No. 4, s. 132-136.

RICHARD, G and ADAM, B. (1999). The Induced Innovation Hypothesis and Energy-saving Technological Change. Quarterly Journal of Economics.1999, No.114, s.941-975.

SHAN, H.J. (2008). China Capital Stock K Re-Estimate: Year 1952-2006. Quantitative Economic and Technical Economic Research. 2008, No.10, s. 17-31.

SHEN, N. (2010). Energy Input, Pollution Emission and Regional Spatial Distribution of Energy Economy Efficiency in China. Finance and Economics. 2010, No.1, s,107-113.

SIMS, C. A. (1980). Macroeconomics and Reality. Econometrica. 1980, Vol.48, No.1, s. 1-48.

SINTON, J. E, and FRIDLEY, D. G. (2000). What Goes Up: Recent Trends in China's Energy Consumption. Energy Policy. 2000, Vol.28, No.10, s. 671-687.

WANG, W. J. and XIANG, Q. F. (2014). Adjustment of Industrial Structure and Potential Assessment of Energy Saving and Carbon Reduction. China Industrial Economics. 2014, No.1, s. 44-56.

WU, A. H., CAO, Y. Y. and LIU, B. (2014). Energy Efficiency Evaluation for Regions in China: An Application of DEA and Malmquist Indices. Energy Efficiency. 2014, Vol.7, No.3, s. 429-439.

WU, Q. Q. and DONG, X. (2016). Study on the Energy Efficiency of the Yangtze River Economic Belt under Environmental Constraints. China Soft Science. 2016, No. 3, s. 73-83.

XU, X. Z. and GUAN, J.W. (2011). Regional Energy Efficiency Convergence in China: Based on The Perspective of Space Economics. Financial Research. 2011, Vol. 37, No.1, s. 112-123.

YU, B. B. (2017). How Industrial Restructuring Improves Regional Energy Efficiency? - An Empirical Study Based on the Two Dimensions of Amplitude and Quality. Financial Research. 2017, No.1, s. 86-97. 